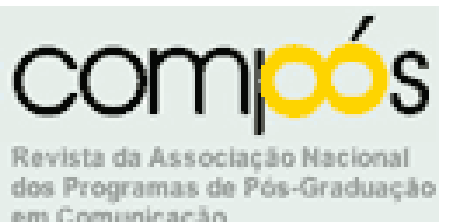

Este artigo foi publicado na edição 1, em dezembro de 2004, da revista eletrônica e-compós: http://www.compos.org.br/e-compos

\title{
CULTURA MIDIÁTICA E GRUPOS SOCIAIS: POSSIBILIDADES DE UM CAMPO DE ESTUDOS
}

Bárbara Heller, Haydée Cardoso, José Gatti, Solange Wajnman
Universidade Paulista

Você pode estar na mídia sem saber porquê. Você pode ser dono de uma rede de TV. Você pode dar o fora tendo tudo pra ficar. Adotar um nome diferente, você pode mesmo se isolar. Mas um dia vai servir a alguém, é. Seja ao Diabo.Ou seja a Deus. Um dia você vai servir a alguém.

Gotta serve somebody/ Um dia você vai servir a alguém

Bob Dylan, versão de Vitor Ramil

O Programa de Mestrado em Comunicação da Universidade Paulista tem como área de concentração Comunicação e Cultura Midiática. Apresentaremos aqui alguns dos marcos teóricos que orientam a linha de pesquisa Cultura Midiática e Grupos Sociais, assim como alguns dos projetos que temos desenvolvido. De acordo com a definição estabelecida no projeto do Programa, esta linha de pesquisa privilegia "o estudo de grupos sociais em sua relação com os meios, linguagens e processos da comunicação e da cultura midiática, dando particular atenção aos efeitos sociais da cultura dos media e aos modos de recepção das mensagens e produtos midiáticos por 
parte de tais grupos". Como definir cultura midiática? De que maneira essa cultura se relaciona com os grupos sociais? Essas são algumas das questões que nos colocamos em nosso trabalho diário. Este texto, sem pretender respondê-las, procurará apontar alguns dos caminhos que temos seguido.

\section{O Campo da Comunicação}

Em primeiro lugar, vale lembrar que a grande área da Comunicação Social sofreu (e ainda sofre, em grande medida) de uma síndrome típica de jovens áreas de conhecimento - a saber, de um desejo incontido de definir sua própria especifidade. Essa síndrome se abate de forma notória em nossa área, cujo próprio surgimento foi marcado pela interdisciplinaridade. Lembro-me de que no final dos anos 1960, calouro na antiga Escola de Comunicações Culturais da Universidade de São Paulo, surpreendia-me a bibliografia de matizes variados que nos era apresentada, incluindo títulos da física (de que outra maneira explicar um conceito como "entropia”?), da sociologia (predominantemente funcionalista, de origem norte-americana), das artes plásticas (memoráveis, as aulas da profa. Maria Luisa Scuderi) e mesmo a disciplina Teoria da Comunicação oscilava entre a semiótica (com a presença marcante do prof. Eduardo Peñuela-Canizal), das letras (era o prof. Dino Preti que nos apresentava a linguagem audiovisual), a contribuição de Marshall McLuhan ("O meio é a massagem", lembram-se?) e as teses da Escola de Frankfurt (introduzidas pela profa. Anamaria Fadul). Entretanto, o que se ouvia nos corredores da antiga Escola de Comunicações Culturais da USP era um freqüente lamento pela "falta de originalidade teórico-epistemológica" da área.

Muitos acadêmicos brasileiros da comunicação passaram as décadas seguintes buscando criar um campo teórico próprio. Ainda hoje essa preocupação - a de se definir o que é próprio ou não da área, freqüentemente em detrimento da interdisciplinaridade - muitas vezes impede o aporte de conhecimentos que poderiam contribuir para renovar definições

de objetos, paradigmas e metodologias. É curioso que áreas plenamente estabelecidas como a História, os Estudos Literários e mesmo as Ciências Sociais não demonstrem essa insegurança epistemológica e se apresentem muito mais abertas à interdisciplinaridade. 
Hoje, em pleno século XXI, não se pode dizer que a área da Comunicação Social tenha a mesma juventude que tinha em 1968. E não se justifica a fobia de interdisciplinaridade que ainda se verifica em certos setores da academia brasileira, que se julgam capazes de definir com absoluta clareza o que é e o que não é da área da Comunicação. (Sabemos como esse tipo de julgamento muitas vezes se torna nefasto, engessando pensamentos, abortando projetos e - o que não é nada prosaico - cortando verbas e bolsas de pesquisa).

Em nossa linha de pesquisa, por nossa própria formação variada, temos buscado criar um diálogo interdisciplinar. Isso se faz necessário pela própria definição de nossa área de concentração, ou seja, Comunicação e Cultura Midiática, e isso emerge na linha de pesquisa Cultura Midiática e Grupos Sociais.

Em nossos trabalhos temos procurado, por meio do entrecruzar de perspectivas analíticas situadas no campo da chamada teoria social, desenvolver conhecimentos a respeito não somente de linguagens, veículos e práticas, mas principalmente em torno de fenômenos comunicacionais os mais diversos, que ocorrem no âmbito das relações empreendidas entre grupos sociais específicos em suas interações com a mídia.

Correntes teóricas que polemizam concepções como indústria cultural, cultura de massa e sistemas simbólicos têm sido amplamente utilizadas para análises a respeito de mídias em geral. Um dos focos de nosso trabalho tem sido estudar fenômenos comumente definidos como de "cultura popular". Essa escolha já implica numa problemática específica. Os modelos tradicionais de pensar a mídia, como lembra Arlindo Machado, “deixam de lado, como destituídas de interesse, formas marginais, alternativas, autônomas e experimentais de comunicação massiva"1. Coloca-se aqui uma nítida vertente que empreende uma tentativa de reflexão a respeito das diferenciadas articulações que produtores da chamada cultura popular brasileira, por exemplo, têm entabulado com a mídia em específicos contextos históricos, econômicos e sociais.

No momento atual, em que se redefinem conceitos e práticas a respeito de espaço público e espaço midiático, o enfoque dessa vertente mira desenvolver investigações sobre relações estabelecidas entre manifestações culturais e produções midiáticas. Tais reflexões devem levar em consideração o fato de que pessoas

\footnotetext{
1 "Contra a ibopização do pensamento (em defesa da mídia radical)". In Downing, John. Mídia Radical: rebeldia nas comunicações e movimentos sociais (São Paulo: Ed. SENAC, 2002).
} 
desenvolvem seus processos de percepção, imaginação, recordação, etc., de acordo com suas condições e locais onde vivem, como assinala Clifford Geertz².

\section{Cultura, Ideologia, Mídia}

Na tentativa de articulação de um quadro teórico, talvez valha buscarmos algumas definições. A que cultura estamos nos referindo aqui? E mais: o que seria uma cultura midiática? Longe de pretender dar uma resposta unívoca a essas questões, preferimos apresentar alguns dos instrumentos que temos utilizados nessa busca. Entendemos nosso ofício como um processo cujas origens trazem ecos e ressonâncias de nossas experiências anteriores e que poderá levar a caminhos distintos - e não seria gratuita aqui a referência à rede dialógica proposta por Volochinov e Bakhtin, teóricos dos Estudos Literários cujos pensamentos tem sido largamente utilizados em áreas distintas como Ciências Sociais, Estética e Estudos do Audiovisual. É essa rede que pretendemos tecer.

E cultura, para nós, remete a outra referência, a do pensamento de Raymond Williams, fundador dos Estudos Culturais, que se apropria da antropologia para definir cultura como "um determinado modo de vida, seja de um povo, um período ou um grupo"3. É o próprio Williams que nos lembra que história e cultura estão imbricadas, não devendo ser abordadas como entidades separadas. Esta "historicização" da cultura, isto é, sua contextualização temporal e espacial, remete a outro conceito central, que politiza a cultura: o de ideologia. Para Williams, a ideologia tem triplo significado: primeiro, um sistema de crenças específicas de uma determinada classe ou grupo; segundo, um sistema de crenças ilusórias -- falsas idéias ou falsa consciência -- que podem ser cotejadas com o conhecimento verdadeiro ou científico; terceiro, o processo geral dos sentidos e das idéias ${ }^{4}$. Em que pesem as dificuldades de se abarcar todas essas possibilidades, nosso trabalho tem sido marcado por essa baliza.

Nesse sentido, o termo mídia também deve ser contextualizado, pois sua etimologia revela seu lugar na cultura e na(s) ideologia(s). Mídia tem origem na

\footnotetext{
${ }^{2}$ O saber local. (Petrópolis: Vozes, 1998)

${ }^{3}$ Keywords (London: Fontana, 1983), p. 90.

${ }^{4}$ Idem, pp. 152-157.
} 
palavra inglesa media, ou seja, meios, que por sua vez se enraiza na palavra latina media -- plural de medium. Essa ascendência poliglótica e híbrida nos faz pensar no momento histórico em que vivemos, quando recorremos à anglofonia para resgatar um termo da própria língua que deu origem ao galaico-português ${ }^{5}$. Neste sentido, pode-se dizer que a adoção desse termo resulta de uma trajetória elíptica, em que as relações de poder parecem ser capazes de abortar atalhos que pareceriam óbvios. E mais: o aportuguesamento de media se faz de acordo com as convenções de uma heteroglossia em que prepondera uma pronúncia pseudoinglesa. Este momento, de uma globalização dominada por hegemonias intimamente ligadas ao complexo industrial-cultural (e, por conseqüência, à anglofonia), resulta de um século de expansão das mídias (especialmente as audiovisuais) e alcança nosso meio acadêmico praticamente desavisado. (Pergunte-se a qualquer estudante de comunicação a etimologia da palavra mídia).

Uma vez reconhecida a complexidade dessa constelação conceitual, seria interessante notar que mídia, em nosso Programa, é entendida como ambiente, isto é, num âmbito que transcende -- em muito -- os chamados "meios de comunicação". Seja quem você for, estará envolvido por esse ambiente -- e possivelmente estará servindo a alguém, como diz o poeta. Ao mesmo tempo em que evitamos tendências totalizantes, que freqüentemente desembocam em definições e conclusões pouco produtivas, buscamos uma compreensão ampla dos fenômenos que se inserem nesse ambiente, levando em conta as múltiplas articulações que o compõem. E, nessa linha, adotamos também a perspectiva dos Estudos Culturais: todos os fenômenos que participam e se articulam nesse ambiente são objetos válidos de pesquisa, não se restringindo a discriminações do tipo "alta" ou "baixa" cultura6. Temos aqui, portanto, uma concepção de mídia que envolve as dimensões sociais, políticas e culturais da vida humana.

\section{O enfoque interdisciplinar na pesquisa}

\footnotetext{
${ }^{5} \mathrm{O}$ mesmo ocorre com o termo deletar, que o senso comum supõe ser de origem inlgesa, mas que no entanto deriva do latim delere.

${ }^{6}$ Sobre a perspectiva de cultura dos Estudos Culturais britânicos e, especialmente sobre sua apropriação do pensamento de Antonio Gramsci, vide Stuart Hall, "Cultural Studies: Two Paradigms", in Storey, John (ed.) What is Cultural Studies? (London: Arnold, 1996) e sobre a história dos Estudos Culturais na Inglaterra, o excelente trabalho de Maria Elisa Cevasco, Dez Lições sobre Estudos Culturais (São Paulo: Boitempo, 2003).
} 
Consideramos o campo da comunicação como integrante do âmbito das ciências sociais para situarmos os fundamentos apropriados que norteiam as pesquisas desenvolvidas a partir dessa linha de pesquisa. Encontramo-nos num momento especial da história da humanidade, em que, com a aceleração de mudanças nos modos de viver e pensar, reflete-se de modo holístico sobre novos paradigmas nas muitas áreas do conhecimento, como lembra D'Ambrosio7. Também no campo da comunicação muitos paradigmas estão sendo reformulados e, como afirma Maria Immacolata Vassalo Lopes, a complexidade do objeto de estudo na comunicação instaura a diversidade de paradigmas científicos ${ }^{8}$.

A existência de um relativo consenso a respeito da complexidade do fenômeno comunicacional emerge da dificuldade de se delimitar e estudar tal fenômeno, em sua totalidade, por meio de uma só disciplina. Assim como Canclini ${ }^{9}$, Lopes ${ }^{10}$ e França ${ }^{11}$, acreditamos que a pesquisa em comunicação se beneficia também de um desenvolvimento a partir das ciências sociais tradicionais. Segundo estes autores, o campo da comunicação está em processo de constituição. Procura-se definir com clareza seu objeto e sua metodologia, assim como se procura delimitar mais especificamente um campo definido e um novo domínio de saber.

$\mathrm{Na}$ tentativa de firmar a especificidade da comunicação a partir de sua constituição como um campo novo de problemas, Lopes reconhece a necessidade de se recorrer à interdisciplinaridade metodológica. Para a autora, no âmbito da comunicação a pesquisa se configura como processo, mediante uma articulação entre seus componentes que são de ordem paradigmática (níveis ou instâncias) e sintagmáticas (fases ou etapas). No proceder de uma pesquisa, essa estrutura em instâncias e fases é organizada concomitantemente à sua prática, e as diversas instâncias interagem e estão presentes em cada fase. Entre os principais elementos constitutivos da investigação temos: a definição do objeto de pesquisa, a observação, a descrição e a interpretação. Desse modo justifica-se a estratégia metodológica adotada a partir de uma opção específica para uma particular pesquisa em ato, isto é, para pesquisa "que se está fazendo"12.

\footnotetext{
${ }^{7}$ D'Ambrosio, U., A era da consciência. (Uberaba: Petrópolis, 1992).

${ }^{8}$ Pesquisa em Comunicação (São Paulo. Edições Loyola, 2001) pp. 89-110.

${ }^{9}$ Consumidores e cidadãos (Rio de Janeiro: Editora UFRJ,1997).

${ }^{10}$ Lopes, op. cit.

11 "O objeto da comunicação/ a comunicação como objeto". In: Hohlfeldt A., Martinho, L., Franca, V.V. (orgs.) Teorias da Comunicação: conceitos, escolas e tendências. (Petrópolis, Rio de Janeiro: Ed. Vozes, 2001).

${ }^{12}$ Op. cit., p. 104.
} 
Para França, "um roteiro de apresentação dos estudos é uma tarefa complexa, ... supõe escolhas, indica uma perspectiva, enfim, traduz um trabalho de interpretação (do pesquisador, mas também aquele permitido por uma determinada época)"13. A prática de pesquisa nos leva a montar estratégias metodológicas que atendam às características do objeto e dos objetivos da pesquisa. Partimos de três princípios básicos envolvidos na produção de pesquisa, à qual o modelo metodológico deve atender: o princípio da não contradição interna, pelo qual o modelo deve dar conta do tempo em que a pesquisa se inscreve; o princípio da não contradição externa, que exige que se dê conta do tempo histórico presente na obra; e finalmente o princípio da responsabilidade científica, que reclama do autor da pesquisa o desempenho consciente em sua produção ${ }^{14}$.

A nortear as pesquisas considera-se também os seguintes componentes paradigmáticos do modelo metodológico nas instâncias:

A - epistemológica (vigilância epistemológica)

B - teórica (quadros de referência)

$\mathrm{C}$ - metódica (quadros de análise)

D - técnica (construção dos dados)

Não se pode esquecer, contudo, que conhecimentos científicos, apesar de serem balizados metodologicamente, possuem limitações provindas de experiências pessoais, parciais e sujeitas a influências. Isso faz com que o desenvolvimento de sentido crítico e auto-análise seja mister enquanto ponto de partida de reflexões que se queiram rigorosas. "O conhecimento desenvolvido pela ciência é estimulado pela realidade e volta para ela - mas à condição de tanto estabelecer proximidade quanto saber guardar afastamento" 15 .

Como discute Canclini, o crescimento vertiginoso das tecnologias audiovisuais de comunicação tornou patentes as mudanças no desenvolvimento do público e no exercício da cidadania. Atualmente, ressalta o autor, o novo cenário de mudanças sócio-culturais aponta para uma redefinição do "espaço público". A importância que os meios de comunicação assumiram na vida das sociedades "põe em evidência uma reestruturação geral das articulações entre o público e o privado"16. Estas articulações ocorrem no campo de relações entre a circulação dos produtos fabricados pelas

\footnotetext{
${ }^{13}$ In Hohlfeldt, p. 118.

${ }^{14}$ Idem.

${ }^{15}$ Idem ibidem, p. 45.

${ }^{16}$ Op. cit., pp. 26-27.
} 
grandes empresas da mídia e os produtores do que se poderia denominar uma cultura local, regional ou popular. O antes chamado "espaço público" vai lentamente se redefinindo na direção do espaço de comunicação que as grandes empresas da mídia empenham-se em estabelecer.

Ressaltamos ainda as considerações de Arlindo Machado, quando afirma que: muita coisa poderia ser discutida hoje no âmbito da comunicação midiática. Penso nas experiências qualitativas de televisão, na regionalização e especialização de algumas mídias, no impacto da música popular para a definição de identidades alternativas, nas apropriações legais ou ilegais de canais e freqüências de onda, nas mídias populares espontâneas como as rádios comunitárias, nos sites específicos na Internet, nas intervenções radicais na grande mídia, etc. ${ }^{17}$.

Por sua vez, Canclini nota que a esfera pública é "um campo de tradições em concorrência”, "um espaço de heteroglossia" em que "certos significados e tradições são fortalecidos"18. Nesse sentido, interessados em compreender tal heteroglossia, que permeia os muitos discursos e práticas comunicacionais entabuladas por grupos sociais em suas interações com a cultura midiática, temos encaminhado nossas reflexões, tirando proveito da seara interdisciplinar.

\section{Formas de sociabilidade}

O que nos leva a pensar numa sociedade midiática, em que a mídia desempenha papel preponderante. A obra de Michel Maffesoli pode constituir uma das bases teóricas para sustentar as questões dos grupos nessa sociedade midiática, já que propõe uma visão de sociedade e de formas de sociabilidades contemporâneas. Na verdade não há, em Maffesoli, uma definição precisa do termo sociabilidade, mas podemos inferir, a partir de suas explicações, que o termo continente "socialidade" o subsume. Este último englobaria os modos diversos de sociabilidades.

\footnotetext{
${ }^{17}$ In Downing, p. 11

${ }^{18}$ Op. cit., p. 253.
} 
Para Maffesoli, a socialidade encontra-se no conceito durkheimniano de “divino social” 19. Este encontra sua sacralidade nos próprios laços sociais e não num ser propriamente divino. Tais laços expressam uma característica antropológica que é “a incrível pulsão de se reunir, se encontrar, se dar ao outro”. Trata-se, pois, de um contágio social, de uma "efervescência” popular ou ainda de uma energia hedonista. É este divino social, composto de múltiplas microexperiências, de práticas compartilhadas, que constitui, na verdade, o grande reservatório do imaginário social ou ainda das formas ideológicas ou míticas.

Este imaginário coletivo pode tomar formas diversas. Em certas épocas ele se manifesta de maneira macroscópica e "abastece” os grandes movimentos de massa, as diversas cruzadas, revoluções políticas ou econômicas. Expressa-se em valores transcendentes e monovalentes como Deus, o Estado, o Progresso ou a Ciência. Existe aí o gosto pelo longínquo, pelas construções abstratas, pelo desenvolvimento e pelas idéias orientadas em direção ao futuro.

Em outras épocas, o imaginário coletivo se cristaliza de maneira microscópica e vai irrigar em profundidade a vida de uma multiplicidade de grupos sociais. A atenção fica voltada então para o "estar-junto", o próximo, o doméstico, o minúsculo. A vida social encontra sentido em valores imanentes, ou seja, ela é suficiente a si mesma. Neste contexto, as vivências populares não se sublimam em valores transcendentes. Constituem antes o que Worringer chama de valores do Einfühlung; efusão de consciências, empatia.

Neste contexto, o que se nomeia como socialidade incide diretamente na pósmodernidade, pois é nela que os valores tribais (constitutivos da socialidade base) se socializam e se difratam para o conjunto do corpo social. Estes valores supõem um processo de desindividualização, uma unissexualização da aparência, à semelhança dos indivíduos nos pequenos grupos, enfim, um processo de identificação e fusão de consciências. Tais características constituem a vida dos bandos, das associações religiosas, das concentrações musicais e de consumo e dos grupos ligados à ecologia. Os valores tribais supõem também uma solidariedade de base que ressurge hoje nas idéias políticas ou religiosas, nas noções de território ou de país, no renascimento das famílias comunitárias etc.

\footnotetext{
${ }^{19}$ Coletivo NTC, Ciro Marcondes Filho (cord.). Pensar-pulsar : cultura comunicacional, tecnologias, velocidade. (São Paulo, Edições NTC, 1996) pp. 90-91.
} 
Devemos examinar com mais profundidade as características destes grupos contemporâneos. Assim observamos como sendo o padrão dos novos estilos de vida, tribos, microgrupos em que as pessoas se reúnem "em função das solidariedades, da vida cotidiana, das práticas culturais, ou mesmo das pequenas associações profissionais” 20 . São as formas de autocentramento grupal, caracterizado por uma situação de isolamento. Estes grupos, no entanto, segundo o mesmo autor, só existem e permanecem quando se contrapõem à indiferenciação massiva dos grandes centros urbanos. Ou seja, para que o grupo sobreviva é necessário que ele se diferencie e, de certa forma, se isole do resto das pessoas. Agregado, identificado em uma pequena comunidade afetiva, de iguais, cada membro desenvolve sentimentos de sociabilidade e acolhimento, impossíveis de serem expressos na multidão indiferenciada. Através de gestos, símbolos, cores, músicas, modas, formas de se expressar, estas pequenas comunidades identificam seus integrantes e mantêm, com eles, a unidade grupal que os diferencia do resto. Cada um representa nestes grupos um papel, persona, de acordo com os valores e cultura vigente. Sua perfomance, no entanto, é mutável de acordo com os diversos grupos aos quais pertence e transita em suas relações cotidianas. Em sua necessidade de garantir para si uma relativa completude grupal, não importa a cada membro a manutenção da sua individualidade, mas a adoção de papéis (máscaras) em que se evidenciem sentimentos e comportamentos que garantam, ainda que por breves momentos, o envolvimento com o grupo diferenciado.

Dentro deste contexto é interessante o pensamento de Gianni Vattimo, quando este diz que a multiplicação das mídias e das tecnologias contemporâneas são elementos de uma explosão e de uma multiplicação generalizada de Weltanschaungen, de visões de mundo ${ }^{21}$. Assim, nas últimas décadas, culturas e subculturas de toda espécie manifestaram-se à opinião pública. E a natureza destes grupos que consiste numa existência pontual, efêmera e sucessiva, podendo, inclusive, contar com uma linguagem tátil, visual, não-verbal é elemento fundamental desta comunicação.

Pode-se dizer que desde que a sociedade se miniaturiza (clãs, tribos) sua necessidade de emblemas, de totens e de símbolos se faz mais presente. ${ }^{22}$ Pode-se

\footnotetext{
${ }^{20}$ Maffesoli, Michel. O tempo das tribos. O declínio do individualismo nas sociedades de massa. (Rio de Janeiro: Forense-Universitária, 1986), p. 137.

${ }^{21}$ Vattimo, Gianni. La société transparente. (Paris:Desclée de Brouwer, 1990), p. 18.

${ }^{22}$ Maffesoli, Michel, Au creux des apparences. (Paris: Plon, 1990), p. 137.
} 
pensar também que, pelo próprio fato de estas agregações não terem a solidez do vínculo institucional, os laços de solidariedade requerem uma nova natureza, natureza esta da ordem do icônico. De fato, estas agregações repousam sobre um laço fusional, um "nós” concatenado que diverge sob vários aspectos do princípio relacional da modernidade. Trata-se aqui de uma comunicação baseada na lógica da identificação e não mais da identidade, como ocorria nas associações contratuais modernas cujo eixo girava na órbita das classes sociais, dos partidos políticos ou das ideologias.

Assim, observa-se atualmente que o look comum ou a posse de certos gadgets, ou ainda a admiração por certos astros da música são emblemas comuns, constitutivos desta lógica identificatória. Estes elementos são, nas palavras de Vattimo, status symbols, "cartas de membro" que permitem aos grupos reconhecerem-se 23 . Mas, ao mesmo tempo em que tais emblemas permitem a lógica fusional, eles permitem a diferenciação dos membros do grupo do resto da sociedade. Há, pois, um efeito duplo nesta comunicação: a imitação e a singularização.

Poderíamos concluir que a comunicação atual, cuja tendência aproxima-se cada vez mais deste tipo de comunicação não-verbal, insere-se numa nova lógica estetizante. Nesta nova lógica, o elemento transcendente libera-se do contexto utópico das ideologias, veiculado pelos antigos media (os jornais democráticos, o rádio) para migrar em direção ao contexto relacional. Não se trata mais de veicular conteúdos infomativos ou, em última análise, da promessa de felicidade. A linguagem visual, plástica e não-verbal destes múltiplos pequenos grupos parece indicar uma experiência concreta comunitária que se realiza na sua fruição.

Assim, há que se considerar esta experiência como uma verdadeira experiência estética. Segundo Vattimo, a utopia estética dos anos 60 se realiza hoje de forma descomplicada e transformada. Segundo o autor,

a experiência estética explode na sociedade, não sob a pressão do design generalizado e de uma higiene social universal de formas, nem da liberação estético-revolucionária da existência como pensava Marcuse, mas do desdobramento da capacidade de o produto estético "fazer mundo", de operar uma criação de comunidade ${ }^{24}$.

\footnotetext{
${ }^{23}$ Op. cit., p. 94.

${ }^{24}$ Idem, p. 88.
} 
É neste sentido que o objeto estético alcança as ruas de maneiras diversas (moda, ornamento dos shoppings, espetáculos de música, feira de objetos, etc), "fazendo mundo", "criando comunidade". Esta experiência, de algum modo, traz a transcendência, outrora restrita à aura da "verdadeira" obra de arte, para a esfera da imanência. Em outras palavras, podemos dizer que hoje a estética mergulha no ambiente cotidiano, criando neste uma atmosfera sensível e sensual compartilhada, levando Maffesoli a descrevê-la como uma estética barroca. Na experiência urbana atual como na "cena" barroca antiga temos o predomínio da sensação, da aparência, dos efeitos, de tudo, enfim, que se insere no domínio da ambiência e não da percepção concreta.

\section{Alguns Projetos}

Entre os trabalhos que temos realizado dentro da linha de pesquisa Cultura Midiática e Grupos Sociais, resolvemos ressaltar alguns que procuram articular essa relação entre mídia e sociedade.

\section{1.}

A pesquisa Caras amigas, raras leitoras? A formação da mulher leitora no Brasil (1914/1926) transita entre a história das mídias, estudos de gênero e os estudos de recepção. A pesquisa levanta, por meio da análise do periódico Revista Feminina, de ampla circulação no início do século XX, indícios sobre a prática de leitura de brasileiras por meio de cartas e editoriais. Trata-se de um corpus de extraordinária riqueza, em que se pode vislumbrar modos de vida, desejos e preocupações de um segmento social geralmente desprezado pela história oficial. Embora se trate de um único periódico dos vários que configuraram a chamada imprensa feminina no Brasil, não se pode desprezar sua importância, dadas sua longevidade (1914 a 1936) e suas estratégias de manutenção e sobrevivência indicação de exemplares luxuosamente encadernados como sugestão de presente de casamento e de aniversário -, gratuidade por um ano às assinantes que apresentassem dez novas assinaturas e assim por diante.

Muitas assinantes da Revista manifestavam-se preocupadas com o que dar a ler às suas filhas, pediam conselhos sobre determinados autores e títulos, sobre como escrever bem e onde encontrar determinados livros. O periódico também traz em seu interior notícias relativas à venda de livros em suas instalações, à formação de uma biblioteca pública voltada exclusivamente para o público feminino, ao número 
crescente de exemplares a cada triênio, aos saraus, concursos e eventos literários e outros assuntos semelhantes.

Este trabalho é a continuação de pesquisa anterior, O feminino e suas práticas de leitura -- uma análise dos periódicos Revista Feminina (1915-1926); Álbum das meninas (1898-190o) e A cigarra (1914-1930), com suportes teóricos de Roger Chartier e Robert Darnton, entre outros. O foco foi sobre a formação da mulher leitora no Brasil no interior de três periódicos paulistanos femininos do final do século XIX e início do século XX, analisando em seus interiores ensaios e crônicas a favor do alargamento do número de leitoras, anúncios de livros e de livrarias, além de ilustrações (tanto no corpo do texto como na capa). Tais recursos podem ser considerados uma estratégia organizada por um grupo de brasileiras para que um número cada vez maior de mulheres pudesse ter acesso a livros e textos impressos.

Como se pode notar, a análise desses periódicos fica tão mais complexa quanto mais se relacionar com os grupos sociais que o permeiam: o de mulheres assinantes, num primeiro momento e, num segundo, o da sociedade brasileira em geral, de maioria analfabeta até meados dos anos 20 do século passado, cuja mentalidade patriarcal via nos livros em particular e nas publicações impressas em geral uma forte ameaça aos bons costumes de moças de famílias.

\section{2.}

Já Cultura afro-brasileira e documentários no espaço midiático examina algumas relações estabelecidas no âmbito das práticas de comunicação constituídas por um lado, por grupos sociais específicos, comunidades que realizam manifestações culturais mantenedoras de memória e padrões culturais próprios e, por outro lado, por equipes de filmagem que documentaram esses eventos. Tradicionalmente realizadas em praça pública, estas manifestações de extração afro-brasileira vão pouco a pouco se constituindo em torno de processos dinâmicos por meio dos quais seus organizadores articulam, com representantes das instâncias midiáticas, novas condições para obterem visibilidade na mídia para os eventos que produzem. Estudam-se aqui fatos, relações e seus efeitos ocorridos na interação entre equipes de filmagem de documentários cinematográficos realizados em Limoeiro de Anadia, Alagoas; nos municípios de Divisa Nova e Campestre, Minas Gerais; e em Ilhabela, São Paulo.

Este trabalho investiga relações entre grupos sociais específicos, comunidades produtoras de eventos, de manifestações que preservam memória e padrões culturais, 
sua interação com equipes de filmagens de documentários cinematográficos e efeitos resultantes desta interação.

As pesquisas que antecederam este trabalho foram Produtos midiáticos $e$ o mundo do samba e Comunicação: fala e imagem no Carnaval. A primeira estudou alguns dos interesses econômicos exógenos e endógenos às escolas de samba junto à mídia, para dessa maneira melhor compreender o processo através do qual as comunidades de sambistas interagem com empresas que elaboram produtos midiáticos e a influência dessas na reelaboração dos espetáculos carnavalescos. A análise centra-se na investigação das características dessas articulações entre as comunidades de sambistas e seus respectivos espetáculos com as empresas que se dedicam a elaborar produtos midiáticos baseados nesses desfiles.

Comunicação: fala e imagem no carnaval buscou nossas origens, para entender nossas especificidades e questionar sobre papéis reservados ao povo brasileiro no futuro. Perguntou-se: quais habilidades potenciais determinarão as novas competências que se fazem necessárias? Estudar o "mundo do samba" pode permitir a visualização de algumas pistas. Por um lado, temos os efeitos sociais da mídia sobre as Escolas de Samba historicamente bem estabelecidos desde a época em que instituições da imprensa escrita financiavam os primeiros desfiles, na década de trinta (do século 20). Por outro, estabelecendo uma interação essencial com a comunicação midiática, temos as Escolas de Samba que absorvem os efeitos da mídia e suas implícitas correlações econômicas. A partir do momento em que os CDs anuais com os sambas-enredo das principais Escolas passaram a ser distribuídos nacionalmente, a autoria dos sambas voltou a ser coletiva: hoje há quatro ou mais autores para cada samba, pois os direitos autorais estão divididos. As comunidades das Escolas absorvem esses efeitos e reformulam seus espetáculos, devolvendo-os para a mídia a cada ano, criando desfiles únicos e originais.

O projeto investigou, ainda, alguns aspectos da constituição dos desfiles das Escolas de Samba do grupo principal do Rio de Janeiro para o carnaval do ano 2000, que compulsoriamente celebraram os "500 anos de Brasil”, em sua relação com as pautas da mídia. Trabalhando as relações articuladas pelas comunidades produtoras dos sambas-enredo, seus compositores e a mídia, fica claro que está-se pensando na cultura de grupos sociais específicos, sua veiculação pela indústria cultural: CDs, programas televisivos, e sobre aspectos destas relações com a cultura midiática. 


\section{$3 \cdot$}

Glauber Rocha: Intertextualidades dá continuidade a projeto desenvolvido como tese de doutoramento, em que se analisava seis longas-metragens de Glauber Rocha em sua articulação com a produção cultural brasileira. Esta pesquisa propõe ampliar a análise (inter)textual da obra de Glauber Rocha, se estendendo a seus filmes realizados na década de 70, estabelecendo um diálogo de sua filmografia com obras de Euclides da Cunha (Os sertões), Ariano Suassuna (O romance da pedra do reino) e manifestações de cultura popular, como os sambas-enredo das escolas de samba do Rio de Janeiro -- e aqui este trabalho estabelece sua proximidade teórica e metodológica com o projeto Cultura afro-brasileira e documentários no espaço midiático. Além disso, pretende-se aprofundar o exame da obra de Glauber e localizar a presença de sua persona no debate político e cultural da época. Além dos filmes, outro objeto merecerá atenção: o único romance publicado de Glauber, Riverão Suassuna.

Como a obra de Glauber Rocha se apresenta como um exemplo privilegiado de dialogismo e sincretismo no cinema e na literatura, o trabalho tentará demonstrar que práticas articulatórias e sincréticas estão no cerne de seus filmes e de seu romance. Num país tão sincrético como o Brasil, dependendo do compromisso com o realismo desses filmes, é possível identificar práticas culturais sincréticas e estabelecer relações com outras práticas, também sincréticas: movimentos sociais, obras literárias ou musicais.

Como se pode observar, todas as pesquisas aqui referidas têm em comum tanto a preocupação com a cultura midiática, expressa em periódicos femininos de meados do século 20; em cinema de Glauber Rocha da década de 70; e em documentários cinematográficos que possibilitam visibilidade de comunidades na mídia televisiva. Ressalta-se aqui a preocupação com os grupos sociais a ela correspondentes: brasileiras com práticas de leitura, relações de gênero e de poder e, finalmente, comunidades filmadas em seus eventos. Neste sentido, as pesquisas em andamento e as concluídas sugerem possibilidades de um campo de estudos, ao focalizar a relação entre cultura midiática e grupos sociais. 
Bárbara Heller bheller@attglobal.net Haydée Dourado haydeedourado@hotmail.com José Gatti zegatti@uol.com.br Solange Wajnman wajnman@aclnet.com.br 